Research Article

\title{
LncRNA LINC00662 Exerts an Oncogenic Effect on Osteosarcoma by the miR-16-5p/ITPR1 Axis
}

\author{
Miao Yu $(\mathbb{D}$, Weihao Lu $(\mathbb{D}$, Zhenglin Cao $\mathbb{D}$, and Tianhang Xuan \\ Department of Spine Surgery, Foshan Hospital of Traditional Chinese Medicine, Foshan 528000, Guangdong, China \\ Correspondence should be addressed to Zhenglin Cao; caozl6@hotmail.com
}

Received 15 June 2021; Accepted 18 August 2021; Published 28 September 2021

Academic Editor: Prasanna Kumar Santhekadur

Copyright ( $) 2021$ Miao Yu et al. This is an open access article distributed under the Creative Commons Attribution License, which permits unrestricted use, distribution, and reproduction in any medium, provided the original work is properly cited.

Background. Osteosarcoma (OS) is one of the most malignant bone tumors and has a high metastatic rate. Increasing research has demonstrated the vital roles of long noncoding RNAs (lncRNAs) in human cancers, including OS. LncRNA LINC00662 has been revealed to act as an oncogene involved in multiple tumor progression. This study aimed to investigate the expression pattern, function, and regulatory mechanism of LINC00662 in OS. Methods. Patients who underwent OS surgery were involved in this study. Experiments including RT-qPCR, MTT, western blot, FISH, RNA pull-down, luciferase reporter, colony formation, transwell invasion and migration, and sphere formation assay were performed to investigate the regulatory role of LINC00662 in OS. Results. In the present study, our findings demonstrated the upregulation of LINC00662 expression in OS tissues and cells, and high expression of LINC00662 predicted a poor clinical prognosis of patients' iNOS. Through a series of in vivo assays, LINC00662 knockdown suppressed OS cell proliferation, invasion, migration, and stemness property maintenance. Further mechanistical investigations indicated that LINC00662 functioned as a competing endogenous RNA (ceRNA) for sponging microRNA-16-5p (miR-16-5p) to upregulate the expression of IP receptor type 1 (ITPR1) in OS cells. Restoration assays validated the involvement of ITPR1 in LINC00662-mediated regulation of cell functions in OS. Conclusion. LINC00662 exerts oncogenic functions in OS by targeting the miR-16-5p/ITPR1 axis.

\section{Introduction}

OS is a common malignant bone tumor with rapid metastasis, affecting a multitude of people, frequently during adolescence [1-3]. High genetic instability and extreme genome are two main factors contributing to the occurrence and development of OS [4]. Despite significant advances in clinical therapies including surgery, chemotherapy, and radiotherapy, a long-term survival rate for patients with OS remains unsatisfying [5]. Notably, the 5-year survival rate decreases from $77.3 \%$ to $33.9 \%$ when metastasis occurs in OS patients [6]. Considering that the pathogenesis of OS is quite complex [7], it is urgent to investigate the molecular mechanisms underlying OS progression for improvement of the diagnosis and treatment.

Long noncoding RNAs (lncRNAs) are a kind of molecules longer than 200 nucleotides and lack protein-coding ability [8], playing crucial roles in various biological processes via different mechanisms [9]. Accumulating evidence has revealed the regulatory roles of $\operatorname{lncRNAs}$ in tumor progression. For example, lncRNA ASB16-AS1 mediates the proliferation and invasion of hepatocellular carcinoma cells by regulating the miR-1827/FZD4 axis [10]. LncRNA CCAT1 promotes colorectal cancer cell proliferation in vitro and in vivo by upregulating TUSC3 [11]. Multiple lncRNAs have been discovered to participate in OS progression. For example, lncRNA NR2F1-AS1 is overexpressed in OS, and its knockdown suppresses cell proliferation by inducing cell cycle arrest and promotes cell apoptosis [12]. LncRNA SND1-IT1 sponges miR-665 to upregulate POU2F1 expression, thereby facilitating OS cell proliferation and migration [13]. LncRNA LINC00662 has also been reported to be a key regulator of biological behaviors in many cancers. LINC00662 is upregulated in hepatocellular carcinoma and contributes to cell proliferation and invasion through activating Wnt/ $\beta$-catenin signaling pathway [14]. LINC00662 
acts as a miR-34a sponge to promote the tumorigenesis of prostate cancer [15]. LINC00662 has been considered a valuable prognostic biomarker in colon cancer [16]. Since the oncogenic effect of LINC00662 has been well clarified in other cancers, we hypothesized that LINC00662 might play a role in OS. Moreover, LINC00662 has been reported to function as a competing endogenous RNA (ceRNA) by sponging miRNAs in cancers. We thus investigated whether LINC00662 could exert ceRNA functions in OS.

In this research, we aimed to investigate the expression pattern of LINC00662 in OS clinical samples and the function of LINC00662 in OS cell proliferation, migration, invasion, and stemness characteristics, as well as the potential regulatory mechanisms of LINC00662 in OS, which might provide a novel insight for OS diagnosis and treatment.

\section{Materials and Methods}

2.1. Clinical Tissues. OS tissues and adjacent normal tissues from 51 patients who underwent surgical resection were collected from Foshan Hospital of Traditional Chinese Medicine (Guangdong, China) from January 2014 to December 2017. The enrolled patients were within the age of $26-65$, with an average age of $45.87 \pm 11.02$, and they were at different TNM stages (I-VI). All patients were clinically and pathologically diagnosed. None of patients had received any antitumor therapy including radiotherapy and chemotherapy before the operation. The collected tissues were immediately frozen with liquid nitrogen and stored at $-80^{\circ} \mathrm{C}$ until use. All patients signed written informed consent. This study was approved by the Ethics Committee of Foshan Hospital of Traditional Chinese Medicine (Guangdong, China). Follow-up of the patients via phone or return visit was performed every 3 months during the first year after surgery until December 2019 with the observation of overall survival rate of these patients.

2.2. Cell Culture. OS cell lines (U2OS, SAOS-2, 143B, and MG63) and a human osteoblast cell line HFOB 1.19 were all purchased from Cell Bank of Chinese Academy of Sciences (Shanghai, China). Cells were incubated in RPMI-1640 medium (Thermo Fisher Scientific, USA) supplemented with $10 \%$ fetal bovine serum (FBS: HyClone, Shanghai, China), $100 \mu \mathrm{g} / \mathrm{mL}$ streptomycin (Gibco, USA), and $100 \mathrm{U} /$ $\mathrm{mL}$ penicillin (Sigma-Aldrich, USA). The medium was renewed every day. Cells were maintained in a humid incubator at $37^{\circ} \mathrm{C}$ with $5 \% \mathrm{CO}_{2}$.

2.3. Cell Transfection. Short hairpin RNA (shRNA) targeting LINC00662 (sh-LINC0062; 5'-GCUGCUGCCACUGUAAUAATT- $3^{\prime}$ ) and nontargeting shRNA negative control (sh-NC) were purchased from Sangon Biotech Co., Ltd. (St. Louis, USA). MiRNA-16-5p mimics and negative control mimics (NC mimics) were synthesized at GenePharma (Shanghai, China). The pcDNA3.1 vector containing ITPR1 (pcDNA3.1/ITPR1) and the empty vector (pcDNA3.1) were obtained from Genechem (Shanghai,
China). Cell transfection was performed using Lipofectamine 3000 (Thermo Fisher Scientific, Inc., USA). The transfection efficiency was examined by RT-qPCR $48 \mathrm{~h}$ later.

2.4. RNA Extraction and Quantitative Real-Time PCR (RT$q P C R)$. Extraction of total RNAs from OS tissues and cells (U2OS and SAOS-2) was performed using TRIzol reagent (Invitrogen, CA, USA). After quantification with NanoDrop 2000 (Thermo Fisher Scientific), RNA samples were reversetranscribed into cDNA using M-MLV Reverse Transcriptase (Promega, USA). SYBR Green Master Mixture (Takara, Dalian, China) on an ABI 7500 system (Applied Biosystems, USA) was used to evaluate the expression levels of LINC00662 and ITPR1. GAPDH acted as the internal control. SYBR PrimeScript miRNA RT-PCR Kit (Takara) on an ABI 7500 system was used to detect the expression of miR-16-5p. U6 acted as the internal control. Thermal cycles were as follows: $95^{\circ} \mathrm{C}$ for $30 \mathrm{~s}, 95^{\circ} \mathrm{C}$ for $5 \mathrm{~s}$ for 40 cycles, and $60^{\circ} \mathrm{C}$ for $35 \mathrm{~s}$. Relative expression was detected using the $2^{-\Delta \Delta \mathrm{Ct}}$ method. The primers used in this study are shown as follows: LINC00662: Forward, $\quad 5^{\prime}$-CACGCTTCT-
GAAACTGGTGT-3'

Reverse, 5'-TGTACAGCCTGGTGACAGAG-3'

ITPR1: Forward, 5'-GAAGGCATCTTTGGAGGAAGT-3'

Reverse, $5^{\prime}$-ACCCTGAGGA-AGGTTCTG-3'

MiR-16-5p: Forward, 5' -TCCACTCTAGCAGCACGTAAAT- $3^{\prime}$

Reverse, 5'-TCACACTAAAGCAGCACAGTAAT-3'

U6: Forward, 5'-CTCGCTTCGGCAGCACA-3'

Reverse, 5'-AACGCTTCACGAATTTGCGT-3'

GAPDH: Forward, 5'-ACAACTTTGGTATCGTGGAAGG-3'

Reverse, 5'-GCCATCACGCCACAGTTTC-3'

2.5. MTT Assay. U2OS or SAOS-2 cells were seeded in 96well plates $\left(5 \times 10^{3}\right.$ cells/well $)$ in RPMI-1640 medium containing $10 \% \mathrm{FBS}$ at $37^{\circ} \mathrm{C}$. After incubation for $0,24,48$, and $72 \mathrm{~h}$, cells were treated with $0.5 \mathrm{mg} \cdot \mathrm{mL}^{-1} \mathrm{MTT}$ reagent (Sigma-Aldrich, USA). Then, cells were incubated for another $4 \mathrm{~h}$. Next, the formazan precipitate was dissolved with $100 \mu \mathrm{L}$ dimethylsulfoxide (DMSO; Sigma-Aldrich). The absorbance at $570 \mathrm{~nm}$ was detected using a spectrophotometer (Thermo Fisher Scientific, USA).

2.6. Colony Formation Assay. After transfection, U2OS or SAOS- 2 cells were seeded in 6 -well plates $\left(2 \times 10^{5}\right.$ cells/well $)$. The medium was replaced every 3 days. Cells were cultured for 14 days at $37^{\circ} \mathrm{C}$ before the medium was removed. Then, cells were washed with phosphate buffer saline (PBS). Afterwards, the colonies were fixed in $10 \%$ paraformaldehyde for $10 \mathrm{~min}$ and stained with $0.1 \%$ crystal violet solution 
(Beyotime, shanghai, China) for $10 \mathrm{~min}$. The number of colonies was calculated with an inverted microscope.

2.7. Transwell Invasion and Migration Assays. Migratory and invasive ability of OS cells were assessed using a 24-well transwell chamber $(8 \mu \mathrm{m}$; Costar, Boston, MA, USA). For invasion detection, after transfection, $2 \times 10^{5}$ U2OS or SAOS- 2 cells in serum-free medium were added to the upper chamber precoated with Matrigel (BD Biosciences, CA, USA), while the lower chamber was filled with $600 \mu \mathrm{L}$ RPMI1640 medium containing $10 \%$ FBS. After $36 \mathrm{~h}$ of transfection, the invaded cells were fixed with $70 \%$ methanol and stained with $0.1 \%$ crystal violet (Sigma-Aldrich, USA). For migration detection, the upper chamber was not precoated with Matrigel.

2.8. Western Blot Analysis. The lysates of U2OS or SAOS-2 cells were obtained using an RIPA lysis buffer (Beyotime), and protein quantification was performed using a BCA protein assay kit (Pierce, Rockford, USA). Total proteins were separated by $12 \%$ SDS-PAGE gel and transferred onto polyvinylidene fluoride (PVDF) membranes (Millipore, MA, USA), which were blocked with 5\% skimmed milk for $1 \mathrm{~h}$ at room temperature. Then, primary antibodies (all from Boster, Wuhan, China) were incubated with the membranes overnight at $4^{\circ} \mathrm{C}$. Afterwards, the membranes were washed with TBST three times and incubated with horseradish peroxidase (HRP)-conjugated secondary antibodies (Cell Signaling Technology) for $2 \mathrm{~h}$ as per the supplier's protocols. Then, bands were visualized with enhanced chemiluminescence (PerkinElmer, China). The primary antibodies used are shown as follows: CD44 (A00052); Oct-4 (A00174-1); Nanog (A00153-3); GAPDH (A00227); ITPR1 (PB9225).

2.9. Sphere Formation Assay. U2OS and SAOS-2 cells $\left(2.5 \times 10^{3}\right.$ cells/well $)$ were seeded in 6-well ultralow adhesion plates (Corning Incorporated, USA) in serum-free RPMI1640 medium containing $10 \mathrm{ng} / \mathrm{ml}$ epidermal growth factor (Gibco, USA), $0.5 \mathrm{mg} / \mathrm{ml}$ hydrocortisonum (Gibco), $5 \mathrm{mg} /$ $\mathrm{mL}$ insulin (Gibco), and bovine pituitary extract (Gibco). The number of spheres (diameter $>100 \mu \mathrm{m}$ ) was counted under a microscope (Nikon Corporation) after two weeks.

2.10. RNA Fluorescence In Situ Hybridization (FISH). The LINC00662-specific RNA FISH probe was commercially designed and synthesized by RiboBio (Guangzhou, China). A FISH Kit (RiboBio) was used to determine the probe signals. In brief, U2OS, SAOS-2, or HFOB 1.19 cells were fixed in $4 \%$ formalin for $15 \mathrm{~min}$. The cells were hybridized again in hybridization solution at $37^{\circ} \mathrm{C}$ for $30 \mathrm{~min}$ after prehybridization in PBS. Next, DAPI staining (Beyotime) was performed to counterstain the cell nuclei. The images of staining were captured using a fluorescence microscope (Leica, Germany).
2.11. Luciferase Reporter Assay. Wild-type LINC00662 or mutant LINC00662 sequence (mutant at the miR-16-5p binding site), and wild-type or mutant-type ITPR 1 '-UTR sequence were inserted into the pmirGLO vector (Promega, USA) to generate LINC00662-Wt/Mut vectors and ITPR1$\mathrm{Wt} /$ Mut vectors. Afterwards, U2OS and SAOS-2 cells were cotransfected with NC mimics or miR-16-5p mimics and the above constructed vectors using Lipofectamine $3000 \mathrm{Re}$ agent (Thermo Fisher Scientific). The luciferase activities were measured using luciferase reporter assay system (Promega).

2.12. RNA Pull-Down Assay. LINC00662 biotin probe and LINC00662 no-biotin probe, as well as miR-16-5p biotin probe and miR-16-5p no-biotin probe, were synthesized by Sangon (Shanghai, China). The cell protein extracts from U2OS or SAOS-2 were collected for incubation with the RNA or NC probes overnight. Then, the lysate was added with streptavidin agarose beads (Life Technologies) and incubated for another $1 \mathrm{~h}$ at room temperature. Next, these beads were boiled in SDS buffer and purified by RNeasy Mini Kit (Qiagen, USA). The purified RNA was detected by RTqPCR.

2.13. Statistical Analysis. All data are presented as the mean \pm standard deviation (SD). Statistical analysis was performed with SPSS 19.0 software (SPSS, Chicago, USA). Statistical differences between two groups were analyzed using student's $t$-test and those among groups using oneway analysis of variance (ANOVA). $P<0.05$ was considered statistically significant. All experiments were conducted more than three times.

\section{Results}

3.1. LINC00662 is Upregulated in OS Tissues and Cells. Design of the present study is shown in Supplementary Figure 1. To determine the role of LINC00662 in OS, we first detected the expression of LINC00662 in 51 paired OS tissues and adjacent normal tissues using RT-qPCR. The results showed that LINC00662 expression was higher in OS tissues than in normal tissues $\left({ }^{*} P<0.01\right.$; Figure $\left.1(\mathrm{a})\right)$. Subsequently, the expression of LINC00662 in OS cells was measured. As expected, LINC00662 expression was significantly upregulated in OS cell lines (U2OS, SAOS-2, 143B, and MG63) compared with the human osteoblast cell line HFOB $1.19\left({ }^{* *} P<0.01\right.$; Figure $\left.1(\mathrm{~b})\right)$. U2OS cells exhibited the highest level of LINC00662, followed by SAOS-2 cells. Therefore, U2OS and SAOS-2 cells were used for further assays. To investigate whether LINC00662 expression is correlated to the clinicopathological characters of patients, 51 patients were divided into a low-LINC00662-expression group $(n=25)$ and a high-LINC00662-expression group $(n=26)$ according to the median LINC00662 expression. As shown in Table 1, the high-LINC00662 level was significantly related to distant metastasis $(P<0.001)$, TNM stage $(P<0.001)$, and tumor size $(P=0.007)$. To further analyze whether LINC00662 could act as a prognostic biomarker for 


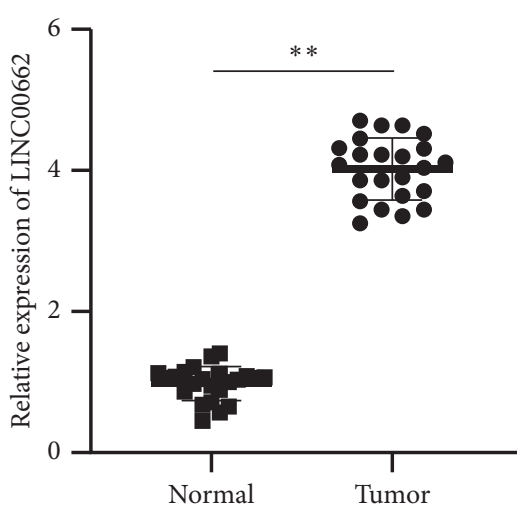

(a)

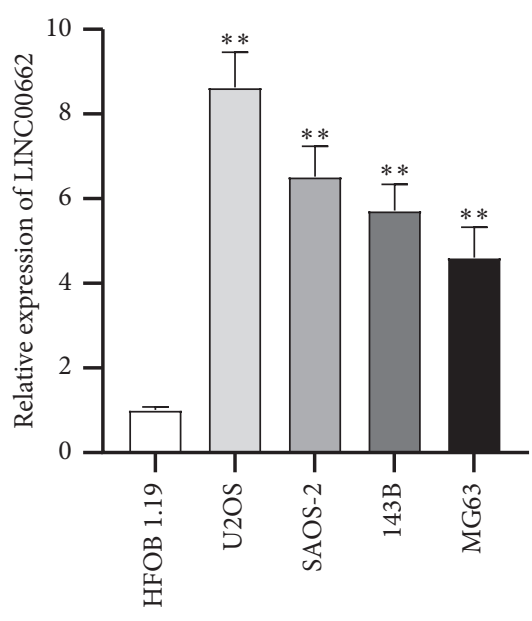

(b)

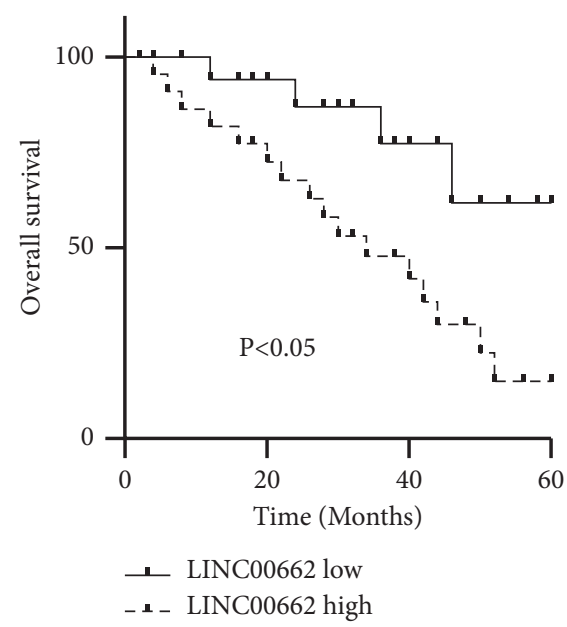

(c)

FIgURE 1: LINC00662 is upregulated in OS tissues and cells. (a) The expression of LINC00662 in 51 OS tissues and adjacent normal tissues was evaluated by RT-qPCR. (b) The expression status of LINC00662 in OS cell lines (U2OS, SAOS-2, 143B, and MG63) and normal human line HFOB 1.19 was measured using RT-qPCR. (c) Overall survival rate of patients with OS using log-rank test and Kaplan-Meier analysis. ${ }^{* *} P<0.01$.

TABLE 1: Correlation between the LINC00662 expression and the clinicopathological characteristics of osteosarcoma patients.

\begin{tabular}{|c|c|c|c|c|}
\hline \multirow{2}{*}{ Characteristics } & \multirow{2}{*}{ Cases } & \multicolumn{2}{|c|}{ LINC00662 expression } & \multirow{2}{*}{$P$ value } \\
\hline & & High $n=26$ & Low $n=25$ & \\
\hline \multicolumn{5}{|l|}{ Gender } \\
\hline Male & 30 & 17 & 13 & \multirow{2}{*}{0.332} \\
\hline Female & 21 & 9 & 12 & \\
\hline \multicolumn{5}{|l|}{ Age } \\
\hline$\leq 60$ & 25 & 12 & 13 & \multirow{2}{*}{0.676} \\
\hline$>60$ & 26 & 14 & 12 & \\
\hline \multicolumn{5}{|l|}{ Morphological type } \\
\hline Classic central OS & 11 & 7 & 4 & \multirow{5}{*}{0.829} \\
\hline Intraosseous well-differentiated OS & 9 & 5 & 4 & \\
\hline Parosteal juxtacortical OS & 13 & 6 & 7 & \\
\hline Periosteal OS & 8 & 3 & 5 & \\
\hline High-grade surface OS & 10 & 5 & 5 & \\
\hline \multicolumn{5}{|l|}{ Anatomic location } \\
\hline Tibia/femur & 39 & 21 & 18 & \multirow{2}{*}{0.342} \\
\hline Elsewhere & 12 & 5 & 7 & \\
\hline \multicolumn{5}{|l|}{ Distant metastasis } \\
\hline Yes & 31 & 22 & 9 & \multirow{2}{*}{0.000} \\
\hline No & 20 & 4 & 16 & \\
\hline \multicolumn{5}{|l|}{$\overline{T N M}$ stage } \\
\hline $\mathrm{I}+\mathrm{II}$ & 27 & 7 & 20 & \multirow{2}{*}{0.000} \\
\hline III + IV & 24 & 19 & 5 & \\
\hline \multicolumn{5}{|l|}{ Tumor size $(\mathrm{cm})$} \\
\hline$\leq 5$ & 19 & 5 & 14 & \multirow{2}{*}{0.007} \\
\hline$>5$ & 32 & 21 & 11 & \\
\hline
\end{tabular}

$P<0.05$ is considered statistically significant (Chi-squared test).

OS, a clinical follow-up study was conducted to determine the overall survival of patients. Kaplan-Meier analysis indicated that the patients in the high-LINC00662-expression group had shorter overall survival compared with those in the low-LINC00662-expression group (Figure 1(c)). In univariate analysis, distant metastasis, TNM stage, tumor size, and increased LINC00662 expression were potential risk factors of shorter overall survival $(P=0.009 ; P=0.040$; $P=0.015 ; P=0.023)$. After adjustment for confounding factors, the multivariate analysis indicated that metastasis 
and increased LINC00662 expression $(P=0.012 ; P=0.013)$ were independently associated with shorter overall survival in OS patients (Table 2).

\subsection{LINC00662 Knockdown Inhibits Malignant Phenotypes of} OS Cells. Since the high expression level of LINC00662 was confirmed, we then intended to explore the role of LINC00662 in OS. RT-qPCR analysis was utilized to check the transfection efficiency of sh-LINC00662 and showed that LINC00662 expression was effectively knocked down in U2OS and SAOS-2 cells after transfection $\left({ }^{*} P<0.01\right.$; Figure 2(a)). The results of MTT and colony formation assays revealed that cell viability and proliferation were significantly inhibited in U2OS and SAOS-2 cells after silencing LINC00662 $\left({ }^{*} P<0.01\right.$; Figures 2(b) and 2(c)). Transwell assays confirmed that inhibition of LINC00662 reduced the invasive and migratory abilities of OS cells $\left({ }^{*} P<0.01\right.$; Figures 2(d) and 2(e)). Additionally, the effect of LINC00662 downregulation on OS stem cell properties was investigated. Western blot analysis showed that the transfection of shLINC00662 decreased the levels of stemness markers (CD44, Oct-4, and Nanog) (Figure 2(f)). Furthermore, sphere formation assay demonstrated that the number of spheroids in U2OS and SAOS-2 cells was reduced by sh-LINC00662 $\left({ }^{*} P<0.01\right.$; Figure $\left.2(\mathrm{~g})\right)$. Overall, LINC00662 inhibits tumorigenic activity in OS cells.

3.3. LINC00662 Acts as a Sponge for miR-16-5p. To investigate how LINC00662 exerts its function, FISH assay was conducted to determine the subcellular localization on LINC00662 in OS cells. The results showed that the majority of LINC00662 was expressed in the cytoplasm of U2OS and SAOS-2 cells, and LINC00662 staining in HFOB 1.19 cells acted as a negative control (Figure 3(a)). Numerous reports indicate that cytoplasmic lncRNA could interact with miRNA to release mRNA by serving as a ceRNA [17]. We thus examined whether LINC00662 could serve as a ceRNA in OS cells. starBase (http://starbase.sysu.edu.cn/index.php) was examined to identify the potential miRNAs. We found three miRNAs (miR-16-5p, miR-34a-5p, and miR-5586-5p) containing binding site on LINC00662 sequence (search category: Pan-Cancer: 10 cancer types) (Figure 3(b)). Then, RNA pull-down assay was used to test the binding between LINC00662 and miRNAs, and the results showed that miR16-5p was most significantly enriched in the LINC00662 probe-biotin group $\left({ }^{*} P<0.05,{ }^{*} P<0.01\right.$; Figure $\left.3(\mathrm{c})\right)$. Next, the transfection efficiency of miR-16-5p mimics in U2OS and SAOS-2 cells was confirmed by RT-qPCR $\left({ }^{*} P<0.01\right.$; Figure 3(d)). Figure 3(e) shows the sequences of miR-16-5p, wild-type LINC00662, and mutant LINC00662. It was revealed by luciferase reporter assay that miR-16-5p overexpression inhibited the luciferase activity of vectors carrying wild type rather than mutant binding site of LINC00662 in U2OS and SAOS-2 cells $\left({ }^{*} P<0.01\right.$; Figure $3(\mathrm{f})$ ). In addition, we found that miR-16-5p was downregulated in OS cell lines $\left({ }^{*} P<0.05,{ }^{* *} P<0.01\right.$; Figure $3(\mathrm{~g}))$ and tissues $\left({ }^{*} P<0.05\right.$; Figure $\left.3(\mathrm{~h})\right)$. Moreover, the downregulated LINC00662 expression was observed in
U2OS and SAOS-2 cells after transfection with miR-16-5p mimics $\left({ }^{*} P<0.05\right.$; Figure $\left.3(\mathrm{i})\right)$. The above findings indicated that LINC00662 can interact with miR-16-5p in OS cells.

3.4. ITPR1 is Directly Targeted by miR-16-5p. To further explore the ceRNA pattern in OS, three online tools (PITA, RNA22, and PicTar) were searched to predict the potential targets of miR-16-5p. Venn diagram displays seven mRNAs (ITPRI, JARID2, ZBTB34, DCAF7, ATXN7L3, FSD1, and BACE1) that might bind to miR-16-5p (Figure 4(a)). RTqPCR revealed that ITPR1 was significantly downregulated in OS cells transfected with miR-16-5p mimics compared with the other mRNAs $\left({ }^{*} P<0.05,{ }^{* *} P<0.01\right.$; Figure $\left.4(\mathrm{~b})\right)$. Furthermore, ITPR1 expression was revealed to be upregulated in OS cell lines and tissues $\left({ }^{*} P<0.05,{ }^{* *} P<0.01\right.$; Figures 4(c) and 4(d)). Meanwhile, ITPR1 expression at mRNA and protein levels was reduced by LINC00662 knockdown or miR-16-5p overexpression, indicating that ITPR1 is positively regulated by LINC00662 and negatively regulated by miR-16-5p $\left({ }^{* *} P<0.01\right.$; Figure $\left.4(\mathrm{e})\right)$. The binding site of miR-16-5p at the $3^{\prime}$-UTR of ITPR 1 is shown (Figure 4(f)). Then, luciferase reporter and RNA pull-down assays were conducted to verify their targeted relationship. As shown in Figure 4(g), the luciferase activity of ITPR1-Wt was significantly inhibited by miR-16-5p mimics, whereas that of ITPR1-Mut presented little change $\left({ }^{*} P<0.01\right)$. ITPR1 was enriched in the complex pulled down by biotinylated miR-16-5p probe $\left({ }^{*} P<0.05\right.$; Figure $\left.4(\mathrm{~h})\right)$, suggesting that ITPR1 is a target gene of miR-16-5p.

\subsection{ITPR1 Reverses the Regulatory Effect of LINC00662} Knockdown in OS Cells. To further test whether ITPR1 expression is responsible for the function of LINC00662, the expression of ITPR1 at mRNA and protein levels was restored using pcDNA3.1/ITPR1 in U2OS cells with LINC00662 silencing $\left({ }^{* *} P<0.01\right.$; Figure 5(a)). As depicted in Figures 5(b) and 5(c), overexpression of ITPR1 significantly restored the LINC00662 silencing-suppressed proliferative activity of $\mathrm{U} 2 \mathrm{OS}$ cells $\left({ }^{* *} P<0.01\right)$. Moreover, ITPR1 overexpression abrogated the suppressive effect of LINC00662 depletion on cell invasion and migration $\left({ }^{* *} P<0.01\right.$; Figures $5(\mathrm{~d})$ and $\left.5(\mathrm{e})\right)$. Meanwhile, the inhibition of LINC00662 knockdown on stemness in U2OS cells was reversed by ITPR1 overexpression $\left({ }^{* *} P<0.01\right.$; Figures 5(f) and 5(g)). Overall, ITPR1 is involved in the LIN00662-mediated regulation of OS cell functions.

\section{Discussion}

In recent years, increasing evidence has revealed that lncRNAs could exert important regulatory functions on the occurrence and development of various cancers, including OS $[9-11,13,18]$, demonstrating the potential research value of lncRNAs in the molecular mechanisms underlying cancer progression. The biological roles of LINC00662 have been studied in a few types of cancers. For example, LINC00662 facilitates cell migration, invasion, and stemness 
TABle 2: Univariate and multivariate Cox analyses of various potential prognostic factors for overall survival in osteosarcoma patients.

\begin{tabular}{|c|c|c|c|c|c|c|}
\hline \multirow{2}{*}{ Variables } & \multicolumn{3}{|c|}{ Univariate analysis } & \multicolumn{3}{|c|}{ Multivariate analysis } \\
\hline & HR & $95 \% \mathrm{CI}$ & $P$ value & HR & $95 \% \mathrm{CI}$ & $P$ value \\
\hline Gender & 0.663 & $0.226-1.944$ & 0.454 & & & \\
\hline Age & 4.108 & $0.888-19.004$ & 0.071 & & & \\
\hline Pathological type & 0.681 & $0.200-2.320$ & 0.539 & & & \\
\hline Anatomic location & 1.261 & $0.379-4.192$ & 0.705 & & & \\
\hline Distant metastasis & 5.293 & $1.519-18.441$ & 0.009 & 4.800 & $1.421-16.216$ & 0.012 \\
\hline TNM stage & 0.236 & $0.059-0.938$ & 0.040 & 0.324 & $0.097-1.081$ & 0.067 \\
\hline Tumor size $(\mathrm{cm})$ & 0.131 & $0.025-0.679$ & 0.015 & 0.315 & $0.093-1.073$ & 0.065 \\
\hline LINC00662 expression & 0.199 & $0.050-0.796$ & 0.023 & 0.212 & $0.062-0.723$ & 0.013 \\
\hline
\end{tabular}

HR: hazard ratio; CI: confidence interval. $P<0.05$ is considered statistically significant (Chi-squared test).
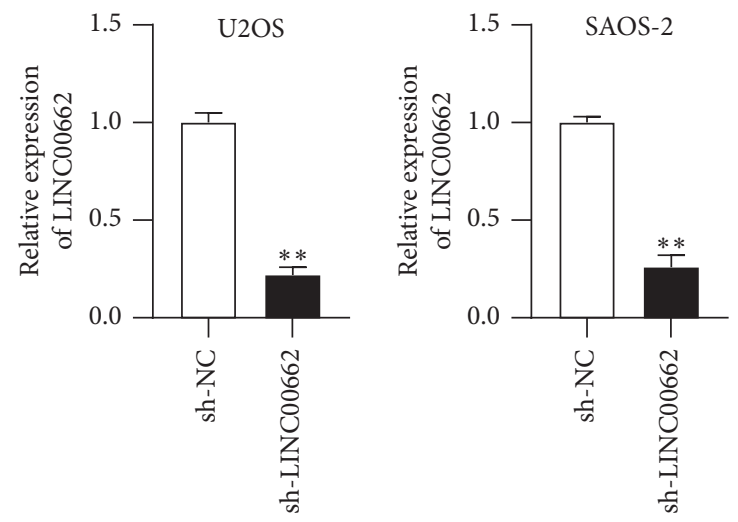

(a)
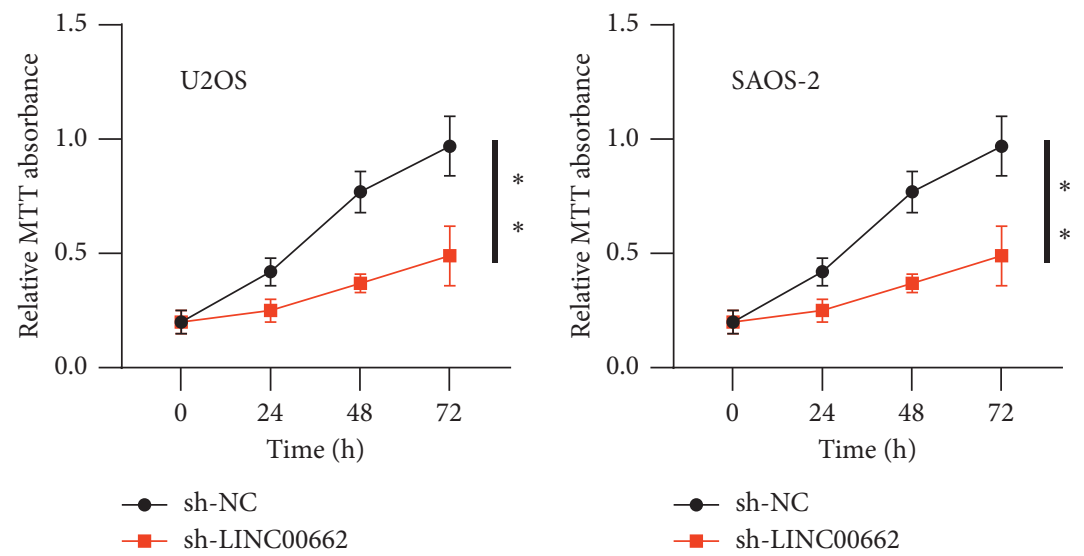

(b)
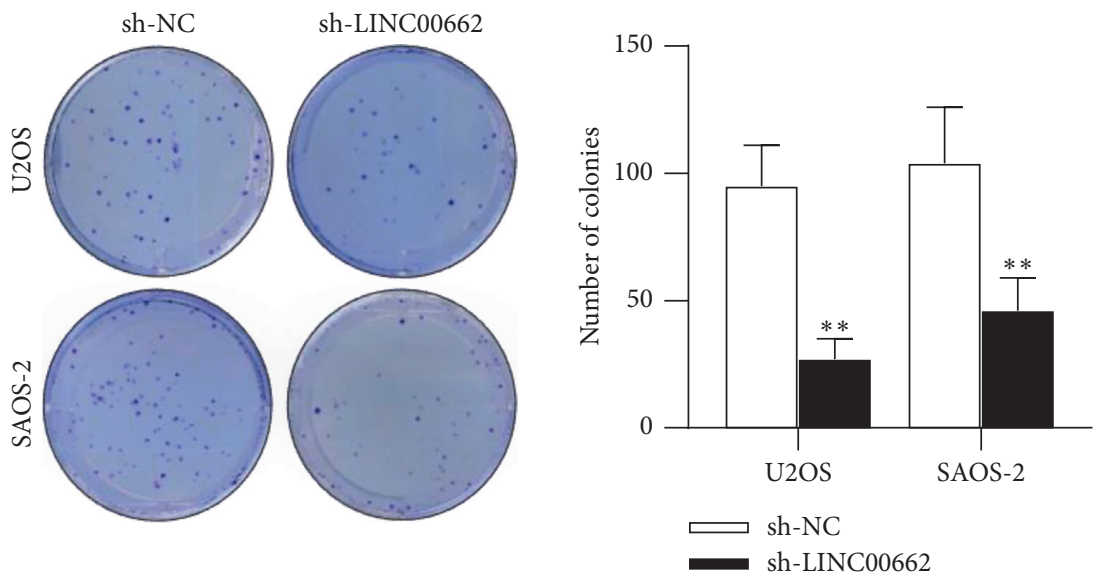

(c)

FIgUre 2: Continued. 

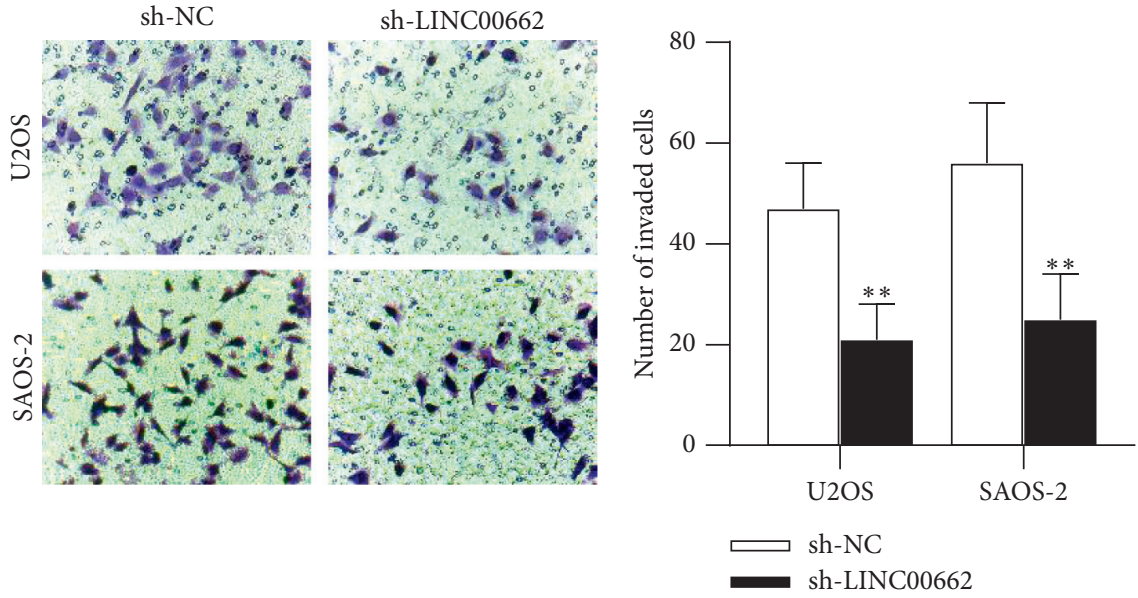

(d)
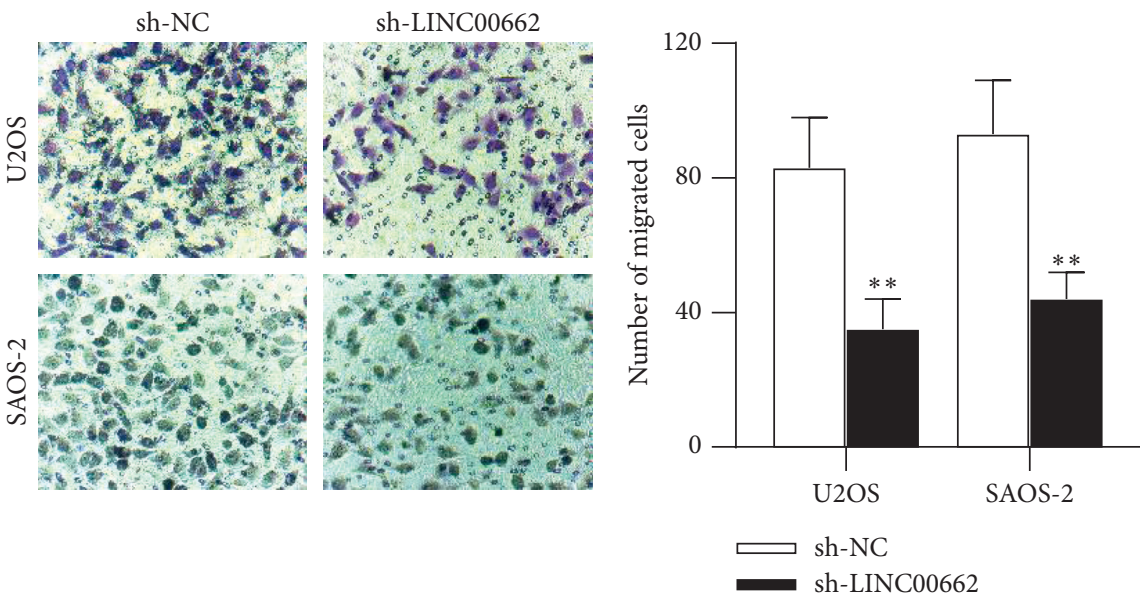

(e)

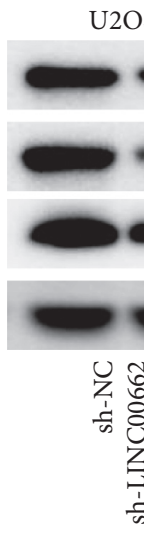

SAOS-2

CD44

Oct-4

Nanog

GAPDH

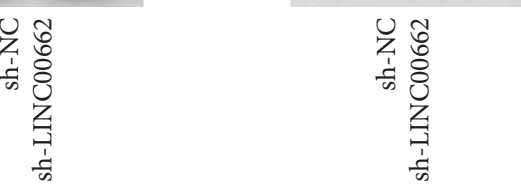

(f)

Figure 2: Continued. 

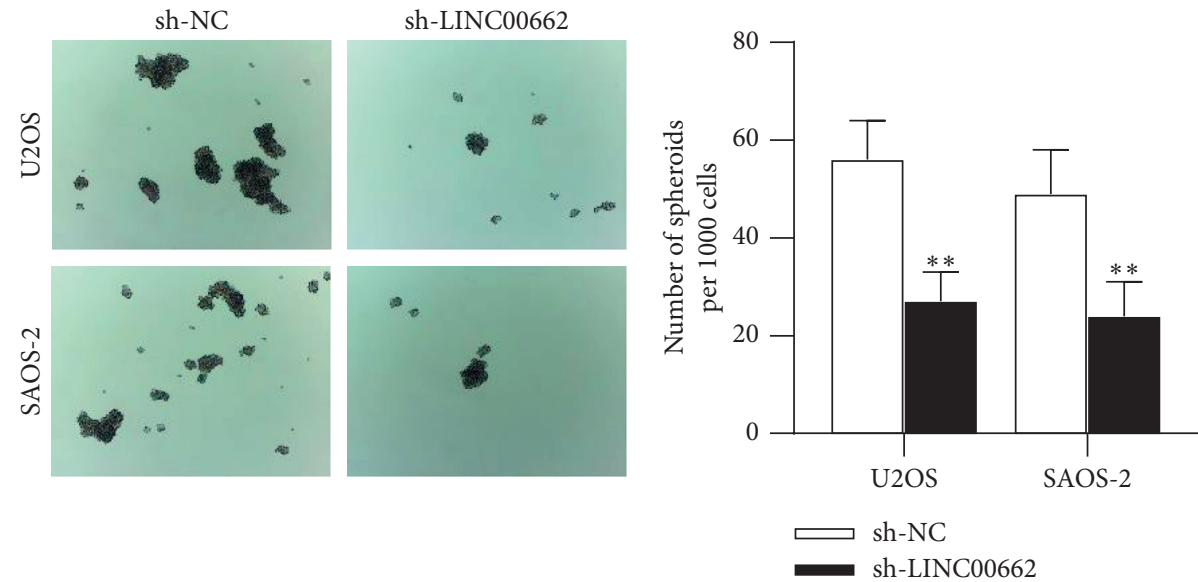

(g)

FIGURE 2: LINC00662 knockdown inhibits the malignant phenotypes of OS cells. (a) The transfection efficiency of sh-LINC00662 in U2OS and SAOS-2 cells was measured by RT-qPCR. (b-c) Cell viability and proliferation in U2OS and SAOS- 2 cells transfected with shLINC00662 were examined by MTT and colony formation assays. (d-e) Transwell invasion and migration assays were performed to assess cell invasion and migration in U2OS and SAOS-2 cells transfected with sh-LINC00662. (f-g) Western blot analysis and sphere formation assay were conducted to examine the impact of sh-LINC00662 in OS stem cell properties. ${ }^{* *} P<0.01$.

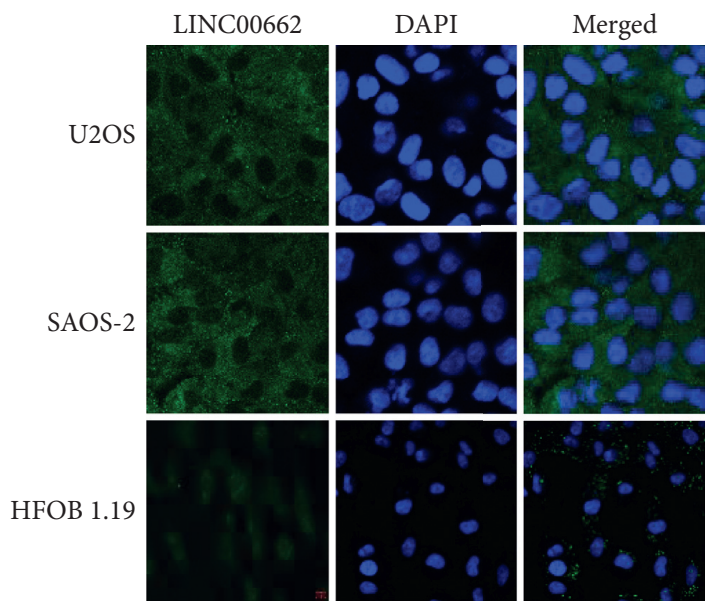

(a)

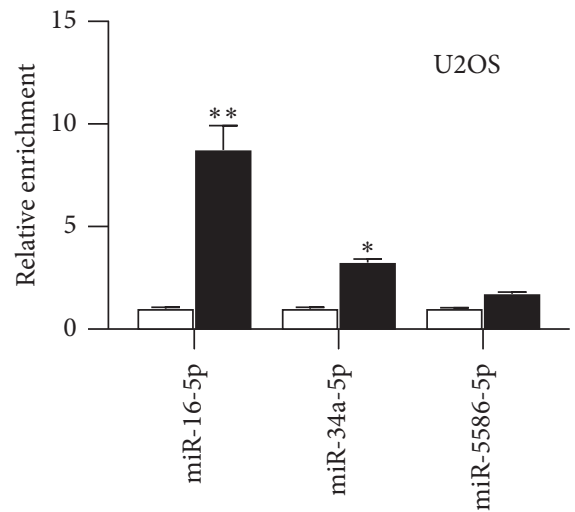

LINC00662 probe-no biotin LINC00662 probe-biotin

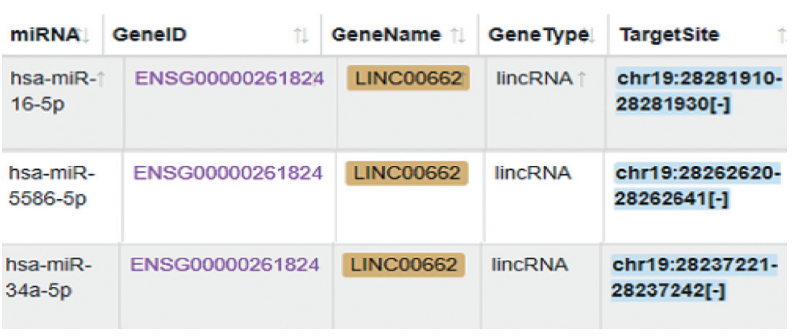

(b)

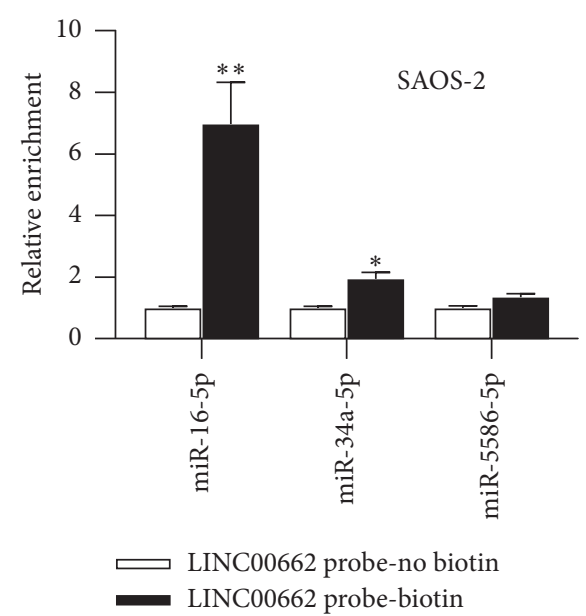

(c)

Figure 3: Continued. 


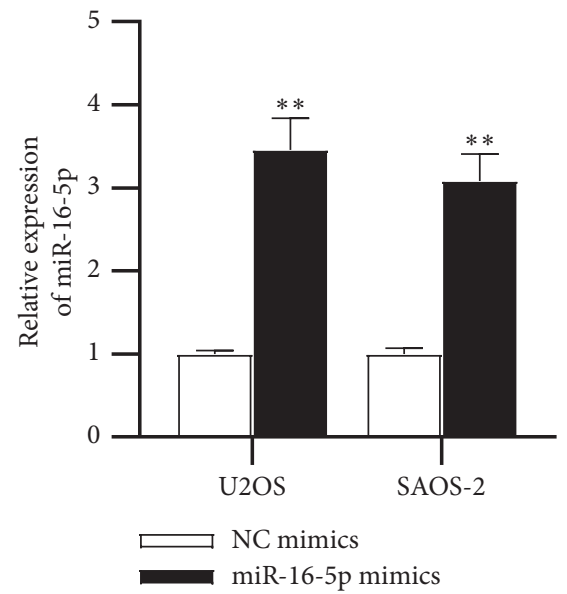

(d)

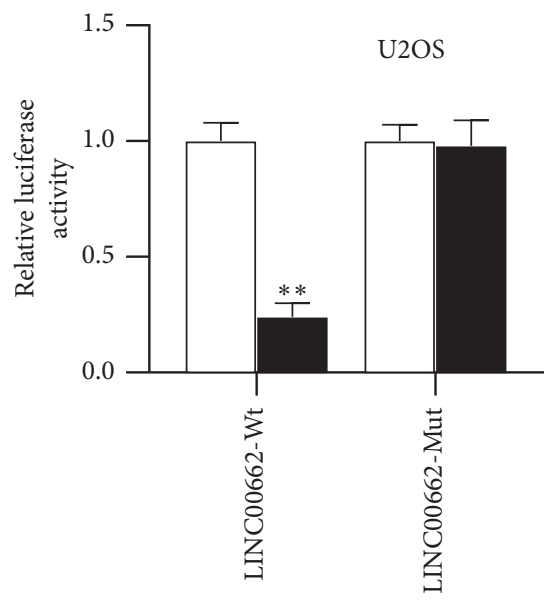

$\Longrightarrow$ NC mimics

miR-16-5p mimics

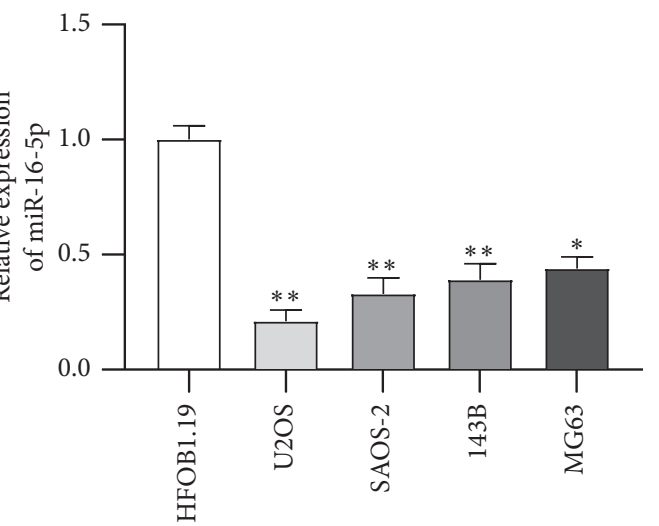

(g)
LINC00662-Wt: 5' aaaaAUUAUUUGACCAUAUGCUGCUu 3'

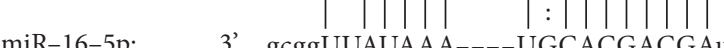

3' gcggUUAUAAA----UGCACGACGAu 5'

LINC00662-Mut: 5' aaaUUAUAAAGACCUGCACGACGAu 3' (e)

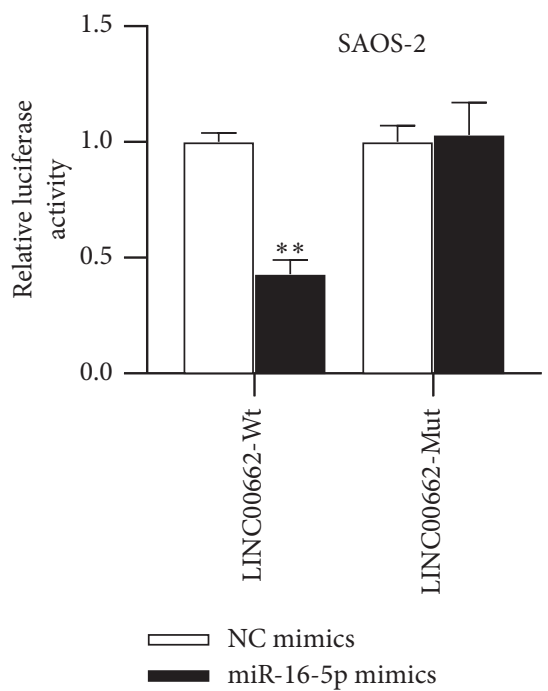

(f)

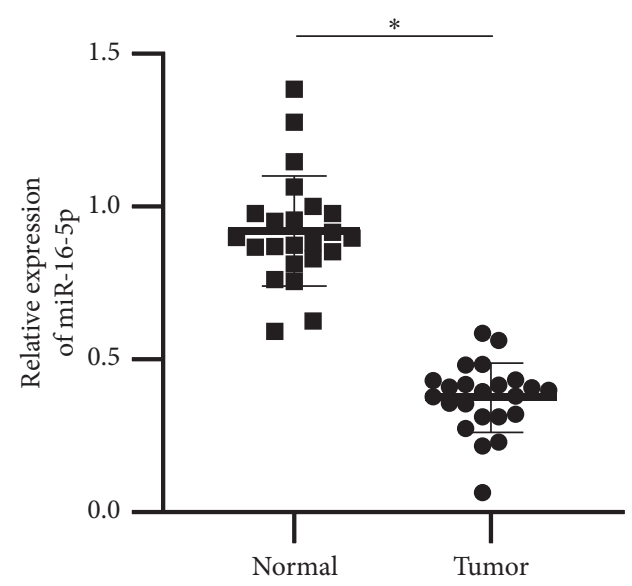

(h)

FIgURE 3: Continued. 


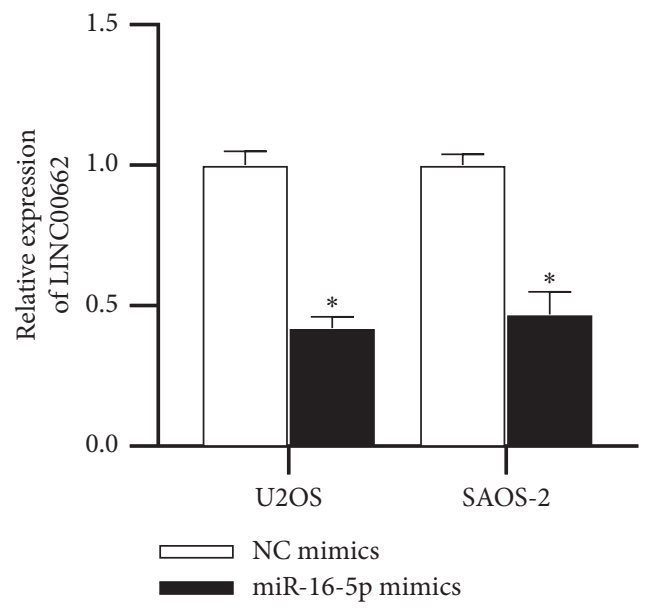

(i)

Figure 3: LINC00662 acts as a sponge for miR-16-5p. (a) The subcellular localization of LINCOO662 in U2OS and SAOS-2 cells was detected using FISH. (b) The possible miRNAs which might bind to LINC00662 were predicted at the starBase website (search category: Pan-Cancer: 10 cancer types). (c) The enrichment of miRNAs in U2OS and SAOS-2 cells was measured using RNA pull-down followed by RT-qPCR. (d) RT-qPCR was carried out to evaluate the transfection efficiency of miR-16-5p mimics in U2OS and SAOS-2 cells. (e) The binding site between LINC00662 and miR-16-5p. (f) Luciferase activities of U2OS and SAOS-2 cells after cotransfection with wild-type or mutant LINC00662 vectors and miR-16-5p mimics or NC mimics. (g) The expression level of miR-16-5p in OS cell lines (U2OS, SAOS-2, 143B, and MG63) and normal human line HFOB 1.19 was detected using RT-qPCR. (h) The expression of miR-16-5p in 51 OS tissues and adjacent normal tissues was evaluated by RT-qPCR. (i) The influence of miR-16-5p mimics on LINC00662 expression was examined by RTqPCR in U2OS and SAOS- 2 cells. ${ }^{*} P<0.05 ;{ }^{* *} P<0.01$.
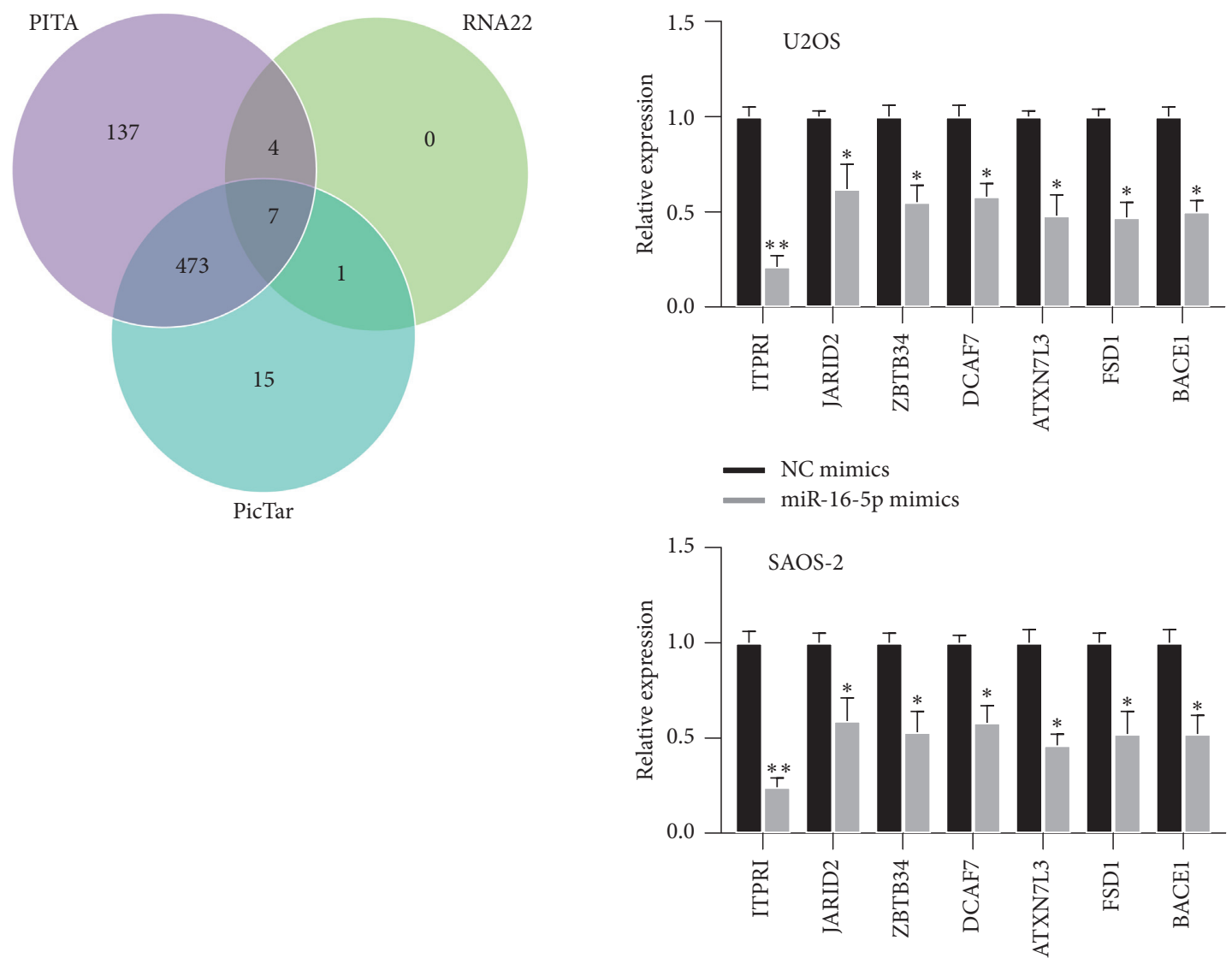

- NC mimics

miR-16-5p mimics

(a)

(b)

Figure 4: Continued. 


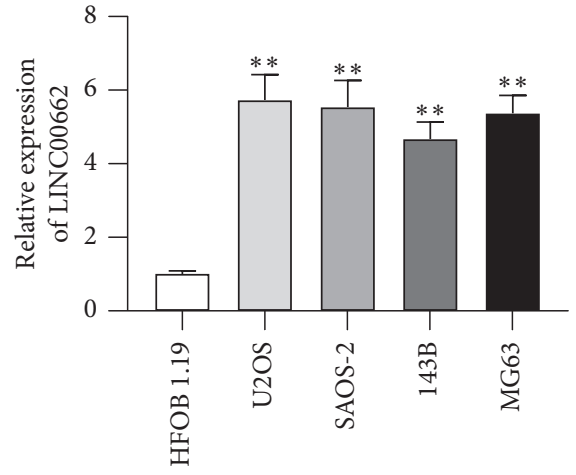

(c)

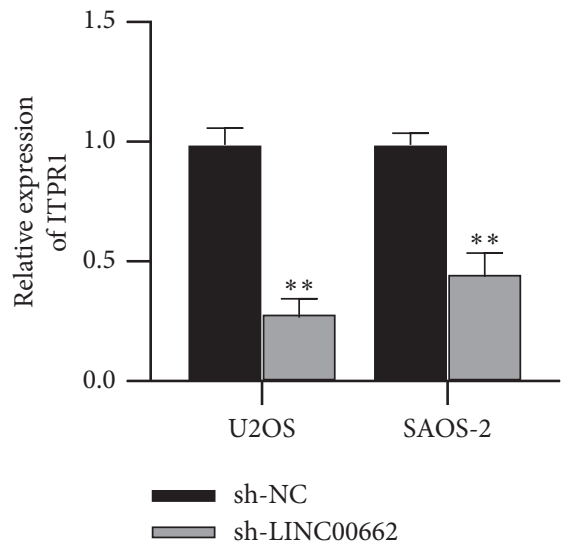

(e)

ITPR1-Wt: 5' uuaacuuucaaAUGAUGCUGCUg 3'

|: | | | | | ||

miR-16-5p: 3’ gegguuauaaaUGC-ACGACGAu 5'

ITPR1-Mut: 5' uuaacuuucaaUGCAACGACGAu 3'

(f)
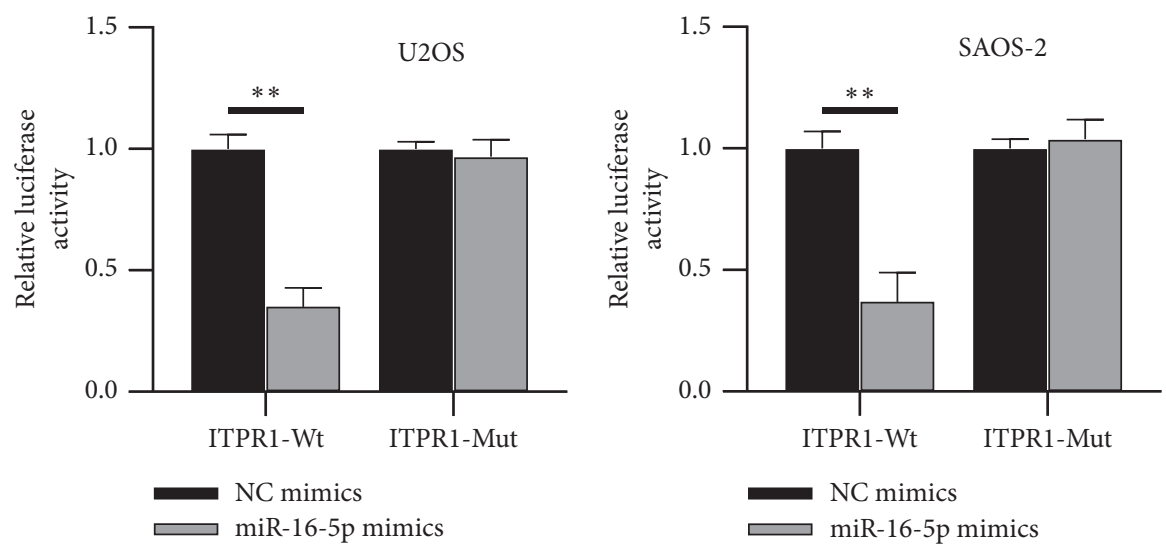

(g)

FIGURE 4: Continued. 


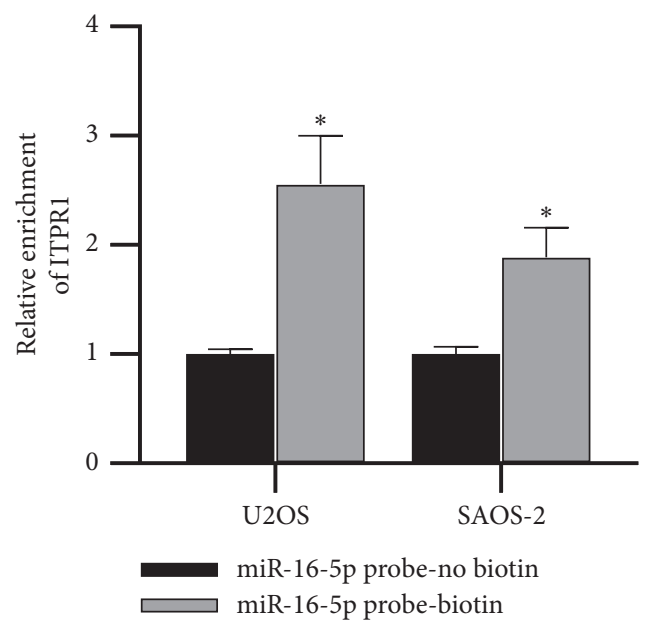

(h)

FIgURE 4: ITPR1 is directly targeted by miR-16-5p. (a) The possible mRNAs binding to miR-16-5p were predicted by PITA, RNA22, and PicTar databases. (b) The expression of candidate mRNAs in U2OS and SAOS-2 cells transfected with miR-16-5p mimics was measured by RT-qPCR. (c-d) RT-qPCR was performed to determine the expression of ITPR1 in OS cell lines and tissues. (e) The impact of sh-LINC00662 or miR-16-5p mimics in ITPR1 expression was examined by RT-qPCR. (f) The binding site between miR-16-5p and ITPR1 obtained from starBase. (g) Luciferase reporter assay was used to test the interaction between miR-16-5p and ITPR1. (h) Interaction of miR-16-5p with ITPR1 in U2OS and SAOS-2 cells was confirmed by RNA pull-down assay. ${ }^{*} P<0.05 ;{ }^{*}{ }^{*} P<0.01$.
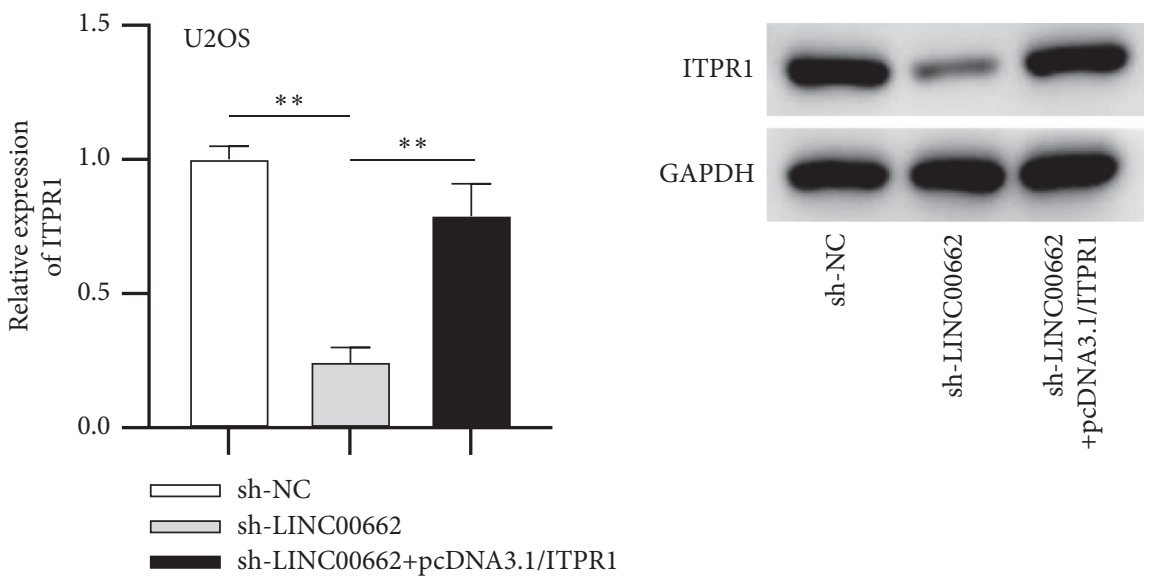

(a)

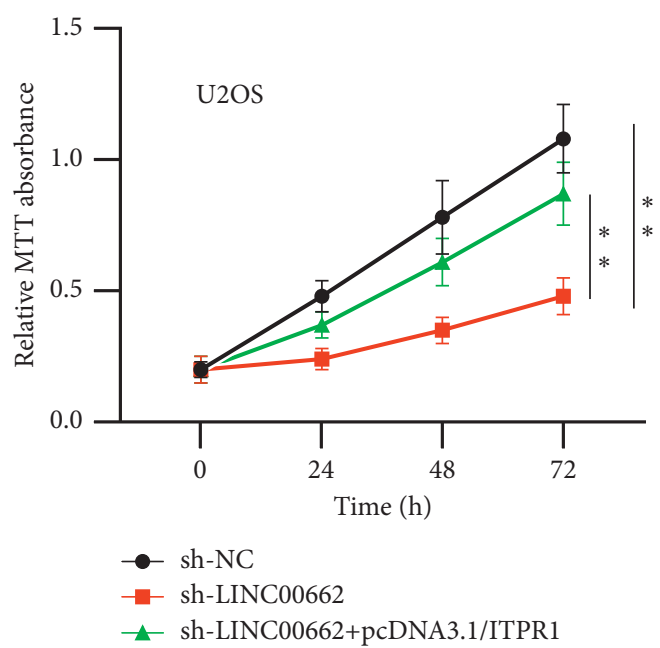

(b)

FIGURE 5: Continued. 

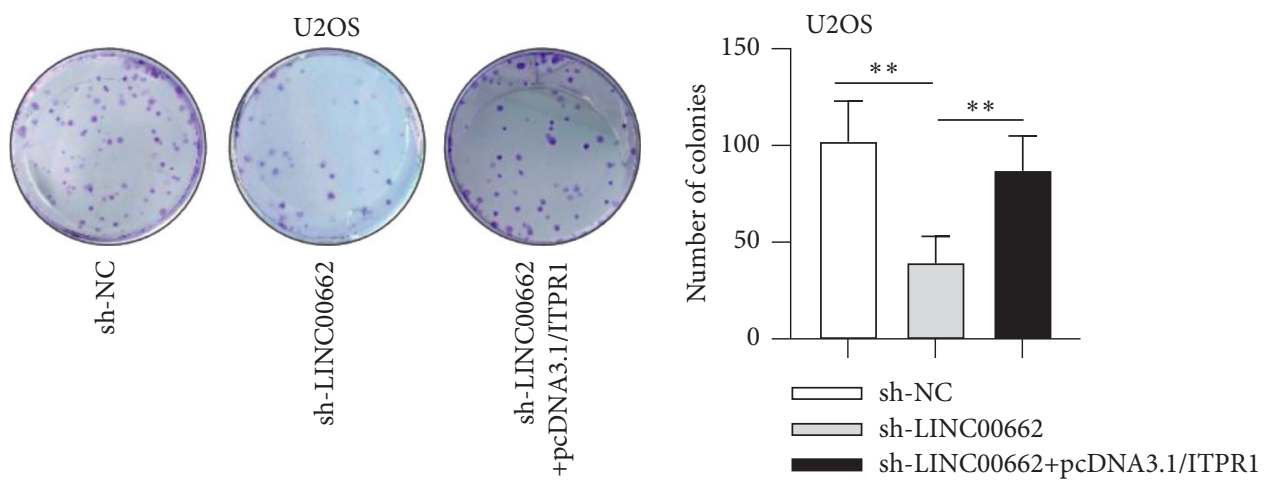

(c)
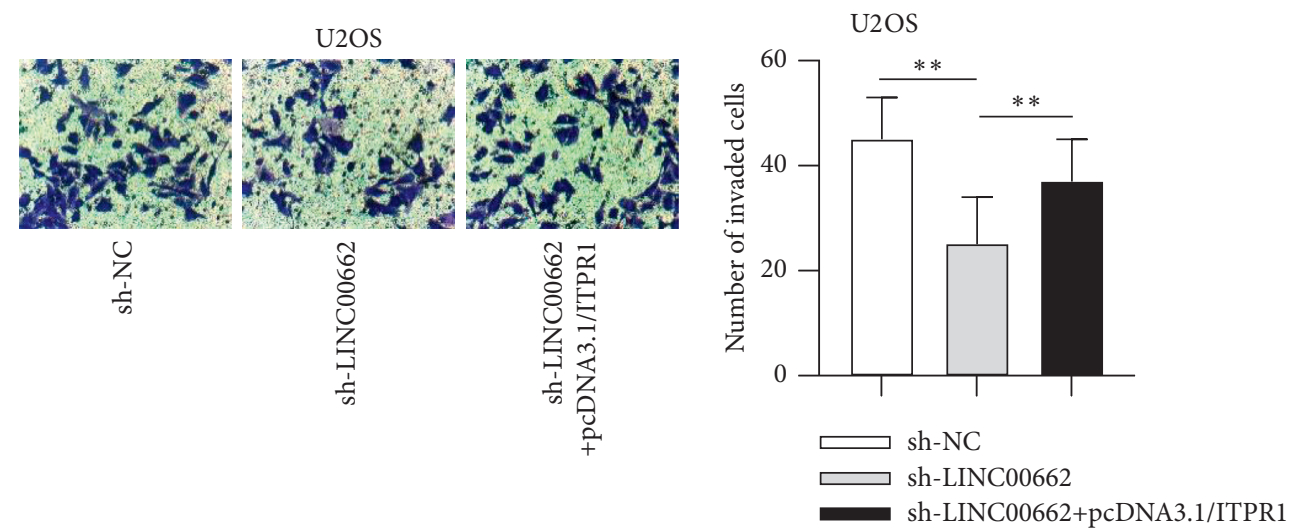

(d)
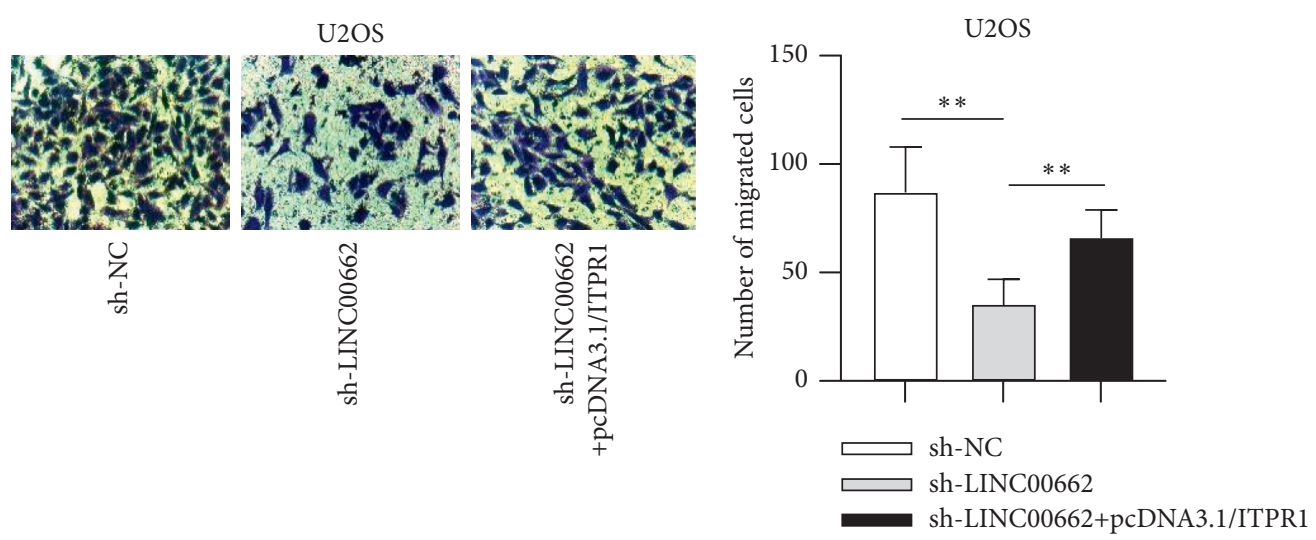

(e)

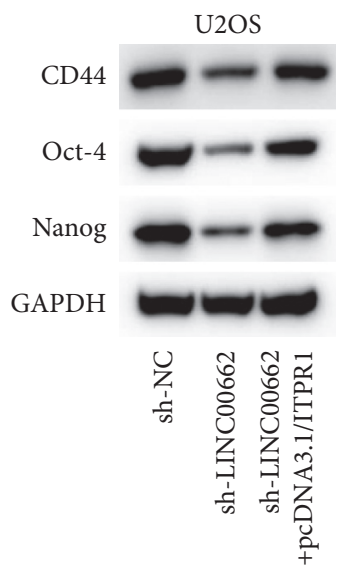

(f)

Figure 5: Continued. 

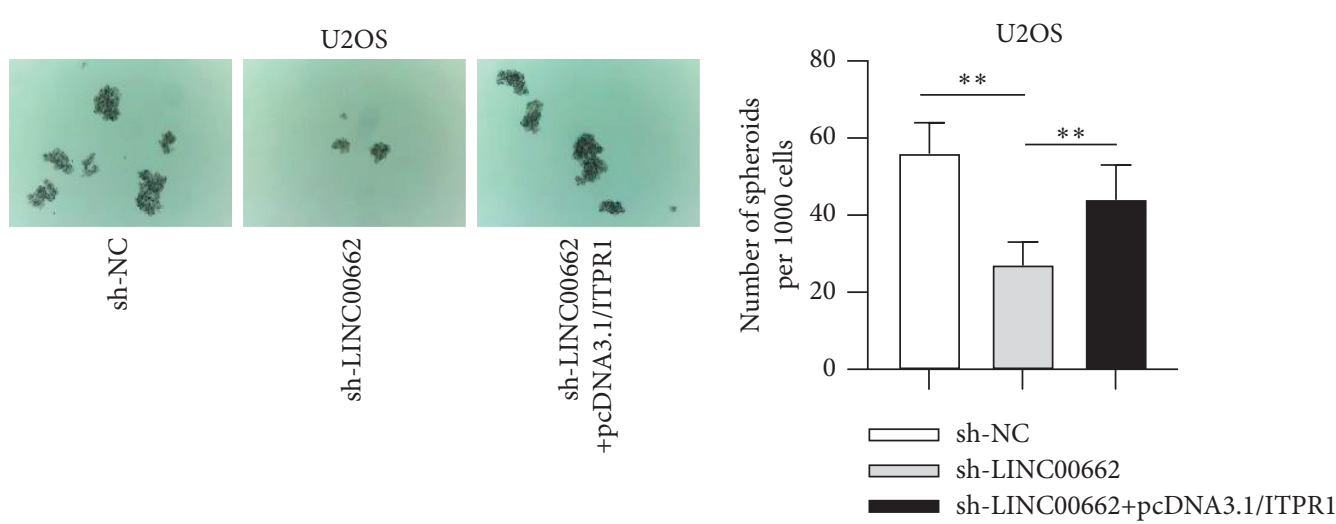

$(\mathrm{g})$

FIGURE 5: ITPR1 reverses the regulatory effect of LINC00662 knockdown in OS cells. (a) U2OS cells were transfected with sh-NC, shLINC00662, or sh-LINC00662 + pcDNA3.1/ITPR1, and the expression of ITPR1 in the transfected cells was measured by RT-qPCR. (b-c) Cell viability and proliferation in the transfected U2OS cells were detected using MTT and colony formation assays. (d-e) Cell invasion and migration in the transfected U2OS cells were evaluated by transwell invasion and migration assays. (f-g) Stem cell properties in the transfected U2OS cells were detected by western blot and sphere formation assays. ${ }^{* *} P<0.01$.

maintenance via interacting with LIN28 in lung cancer [19]. Inhibition of LINC00662 reduces cell proliferative, migratory, and invasive abilities of in oral squamous cell carcinoma [20]. LINC00662 mediates the malignant phenotypes of colorectal cancer cells by the miR-145/c-myc axis [21]. In our research, we demonstrated that LINC00662 was significantly upregulated in OS tissues and cell lines and was negatively related to the overall survival of patients with OS. Then, we found that depletion of LINC00662 significantly inhibited OS cell proliferation, migration, invasion, and stem cell properties in vitro. These findings exhibited the carcinogenic role of LINC00662 in OS, which is consistent with the previous studies.

There has been increasing attention drawn to the theory of ceRNA network; that is, lncRNAs function as sponges for miRNAs to modulate the expression of the target genes [22]. Accumulating research has indicated that lncRNAs could exert ceRNA functions in cancers. For example, lncRNA LINC00460 enhances the progression of head and neck squamous cell carcinoma through sponging miR-612 and upregulating AKT2 [23]. LncRNA SPRY4-IT1 binds to miR-6882-3p by competing with TCF7L2 to affect the cell stemness of breast cancer [24]. LncRNA CHL1-AS1 increases the abilities of cell proliferation and migration via sponging miR-6076 to upregulate CHL1 expression in endometrial cancer [25]. In addition, LINC00662 has been reported to serve as a ceRNA in some cancers [26, 27]. In this study, we examined the subcellular localization of LINC00662 in OS cells and found that LINC00662 was mostly distributed in the cytoplasm, suggesting the possibility that LINC00662 might be involved in ceRNA network by sponging miRNAs. MicroRNAs, a group of small ncRNA molecules with 20-24 nucleotides, can prevent the translation or degradation of target mRNAs at the posttranscriptional level [28]. Through online tools, miR16-5p was predicted to bear the complementary base pairing with LINC00662. In this study, LINC00662 was validated to bind to miR-16-5p. Previous investigations have shown that miR-16-5p is differentially expressed and plays a key role in the progression of numerous cancers, such as breast cancer [29], cervical cancer [30], and hepatocellular carcinoma [31]. In the present study, miR-16$5 \mathrm{p}$ was expressed at a low level in OS tissues and cells and negatively related to LINC00662 in terms of expression level. Conclusively, LINC00662 functions as a molecular sponge for miR-16-5p in OS cells.

To further support the ceRNA pattern in OS, the target genes of miR-16-5p were investigated. Based on the bioinformatics tools, ITPR1 (inositol 1,4,5-trisphosphate receptor, type 1) was identified. ITPR1 has been reported to be involved in Ai-lncRNA EGOT-mediated paclitaxel resistance in human cancers [32]. ITPR1 serves as a direct target of EPAS1 and an autophagy regulator to protect renal carcinoma cells against NK-mediated killing [33]. In this study, ITPR1 was verified to be a direct target of miR-16-5p. Meanwhile, ITPR1 was highly expressed in OS tissues and cells. In addition, rescue assays confirmed that overexpression of ITPR1 could reverse the LINC00662 silencinginduced inhibitive effect on OS cell functions.

In conclusion, this study investigated the biological role and regulatory mechanisms of LINC00662 in OS. Our data support evidence that LINC00662 exerts ceRNA function by sponging miR-16-5p to upregulate ITPR1, thereby mediating the malignant phenotypes of OS cells. Our findings might provide an instructive insight for the future exploration of OS treatment.

\section{Data Availability}

The datasets used or analyzed during the current study are available from the corresponding author on reasonable request.

\section{Conflicts of Interest}

The authors declare that they have no conflicts of interest. 


\section{Supplementary Materials}

Supplementary Figure 1: design of the present study. (Supplementary Materials)

\section{References}

[1] R. A. Durfee, M. Mohammed, and H. H. Luu, "Review of osteosarcoma and current management," Rheumatology and Therapy, vol. 3, no. 2, pp. 221-243, 2016.

[2] P. A. Meyers and R. Gorlick, "Osteosarcoma," Pediatric Clinics of North America, vol. 44, no. 4, pp. 973-989, 1997.

[3] B. A. Lindsey, J. E. Markel, and E. S. Kleinerman, "Osteosarcoma overview," Rheumatology and Therapy, vol. 4, no. 1, pp. 25-43, 2017.

[4] L. Zhang, X. Q. Lu, X. Q. Zhou, Q. B. Liu, L. Chen, and F. Cai, "NEAT1 induces osteosarcoma development by modulating the miR-339-5p/TGF- $\beta 1$ pathway," Journal of Cellular Physiology, vol. 234, no. 4, pp. 5097-5105, 2019.

[5] C. Adamopoulos, A. N. Gargalionis, C. Piperi, and A. G. Papavassiliou, "Recent advances in mechanobiology of osteosarcoma," Journal of Cellular Biochemistry, vol. 118, no. 2, pp. 232-236, 2017.

[6] G.-Y. Hung, H.-J. Yen, C.-C. Yen et al., "Improvement in high-grade osteosarcoma survival," Medicine, vol. 95, no. 15, e3420 pages, 2016.

[7] M. Kansara and D. M. Thomas, "Molecular pathogenesis of osteosarcoma," DNA and Cell Biology, vol. 26, no. 1, pp. 1-18, 2007.

[8] J. Jarroux, A. Morillon, and M. Pinskaya, "History, discovery, and classification of lncRNAs," Advances in Experimental Medicine and Biology, vol. 1008, pp. 1-46, 2017.

[9] K. C. Wang and H. Y. Chang, "Molecular mechanisms of long noncoding RNAs," Molecular Cell, vol. 43, no. 6, pp. 904-914, 2011.

[10] X. Yao, G. You, C. Zhou, and D. Zhang, "LncRNA ASB16-AS1 promotes growth and invasion of hepatocellular carcinoma through regulating miR-1827/FZD4 axis and activating wnt/ $\beta$-catenin pathway," Cancer Management and Research, vol. 11, pp. 9371-9378, 2019.

[11] S. Chen, Y. Liu, Y. Wang, and Z. Xue, "LncRNA CCAT1 promotes colorectal cancer tumorigenesis via A miR-181b-5p/ TUSC3 axis," OncoTargets and Therapy, vol. 12, pp. 92159225, 2019.

[12] Y.-J. Tian, Y.-H. Wang, A.-J. Xiao et al., "Long noncoding RNA SBF2-AS1 act as a ceRNA to modulate cell proliferation via binding with miR-188-5p in acute myeloid leukemia," Artificial Cells, Nanomedicine, and Biotechnology, vol. 47, no. 1, pp. 1730-1737, 2019.

[13] X. M. Jin, B. Xu, Y. Zhang et al., "LncRNA SND1-IT1 accelerates the proliferation and migration of osteosarcoma via sponging miRNA-665 to upregulate POU2F1," European Review for Medical and Pharmacological Sciences, vol. 23, no. 22, pp. 9772-9780, 2019.

[14] X. Tian, Y. Wu, Y. Yang et al., "Long noncoding RNA LINC00662 promotes M2 macrophage polarization and hepatocellular carcinoma progression via activating Wnt/betacatenin signaling," Molecular Oncology, vol. 14, no. 2, pp. 462-483, 2019.

[15] Z. Liu, M. Mi, X. Li, X. Zheng, G. Wu, and L. Zhang, "IncRNA OSTN-AS1 may represent a novel immune-related prognostic marker for triple-negative breast cancer based on integrated analysis of a ceRNA network," Frontiers in Genetics, vol. 10850 pages, 2019.
[16] B. Cheng, A. Rong, Q. Zhou, and W. Li, "LncRNA LINC00662 promotes colon cancer tumor growth and metastasis by competitively binding with miR-340-5p to regulate CLDN8/ IL22 co-expression and activating ERK signaling pathway," Journal of Experimental \& Clinical Cancer Research, vol. 39, no. 1, 5 pages, 2020.

[17] Y. Tay, J. Rinn, and P. P. Pandolfi, "The multilayered complexity of ceRNA crosstalk and competition," Nature, vol. 505, no. 7483, pp. 344-352, 2014.

[18] S. Li, K. Zheng, Y. Pei, W. Wang, and X. Zhang, "Long noncoding RNA NR2F1-AS1 enhances the malignant properties of osteosarcoma by increasing forkhead box A1 expression via sponging of microRNA-483-3p," Aging, vol. 11, pp. 11609-11623, 2019.

[19] W. Gong, Y. Su, Y. Liu, P. Sun, and X. Wang, "Long noncoding RNA Linc00662 promotes cell invasion and contributes to cancer stem cell-like phenotypes in lung cancer cells," Journal of Biochemistry, vol. 164, no. 6, pp. 461-469, 2018.

[20] D. Xu, Y. Chen, C. Yuan, S. Zhang, and W. Peng, "Long noncoding RNA LINC00662 promotes proliferation and migration in oral squamous cell carcinoma," OncoTargets and Therapy, vol. 12, pp. 647-656, 2019.

[21] Z. Yao, D. Xu, Z. Li, J. Yao, Z. Pan, and J. Chen, "Long intergenic non-coding RNA LINC00662 contributes to malignant growth of colorectal cancer cells by upregulating c-myc via sponging microRNA-145," Bioscience Reports, Article ID BSR20200011, 2020.

[22] L. Salmena, L. Poliseno, Y. Tay, L. Kats, and P. P. Pandolfi, “A ceRNA hypothesis: the rosetta stone of a hidden RNA language?" Cell, vol. 146, no. 3, pp. 353-358, 2011.

[23] X. Xie, G. Xiong, Q. Wang, Y. Ge, and X. Cui, "Long noncoding RNA LINC00460 promotes head and neck squamous cell carcinoma cell progression by sponging miR-612 to upregulate AKT2," American Journal of Tourism Research, vol. 11, no. 10, pp. 6326-6340, 2019.

[24] X. Song, X. Zhang, X. Wang et al., "LncRNA SPRY4-IT1 regulates breast cancer cell stemness through competitively binding miR-6882-3p with TCF7L2," Journal of Cellular and Molecular Medicine, vol. 24, no. 1, pp. 772-784, 2019.

[25] Y. Shi, J. Zha, M. Zuo, Q. Yan, and H. Song, "Long noncoding RNA CHL1-AS1 promotes cell proliferation and migration by sponging miR-6076 to regulate CHL1 expression in endometrial cancer," Journal of Cellular Biochemistry, vol. 121, no. 3, pp. 2655-2663, 2019.

[26] Z. Zhang, X. Liang, L. Ren et al., "LINC00662 promotes cell viability and metastasis in esophageal squamous cell carcinoma by sponging miR-340-5p and upregulating HOXB2," Thoracic Cancer, vol. 11, no. 8, pp. 2306-2315, 2020.

[27] N. Li, L. Y. Zhang, Y. H. Qiao, and R. J. Song, "Long noncoding RNA LINC00662 functions as miRNA sponge to promote the prostate cancer tumorigenesis through targeting miR-34a," European Review for Medical and Pharmacological Sciences, vol. 23, no. 9, pp. 3688-3698, 2019.

[28] F. Peng, X. Xie, and C. Peng, "Chinese herbal medicine-based cancer therapy: novel anticancer agents targeting MicroRNAs to regulate tumor growth and metastasis," The American Journal of Chinese Medicine, vol. 47, no. 8, pp. 1711-1735, 2019.

[29] L. Ruan and X. Qian, "MiR-16-5p inhibits breast cancer by reducing AKT3 to restrain NF- $\kappa \mathrm{B}$ pathway," Bioscience Reports, vol. 39, no. 8, 2019.

[30] S. Zhang, W. Wang, X. Wu, W. Liu, and F. Ding, "miR-16-5p modulates the radiosensitivity of cervical cancer cells via 
regulating coactivator-associated arginine methyltransferase 1," Pathology International, vol. 70, no. 1, pp. 12-20, 2020.

[31] B. Cheng, F. Ding, C. Y. Huang, H. Xiao, F. Y. Fei, and J. Li, "Role of miR-16-5p in the proliferation and metastasis of hepatocellular carcinoma," European Review for Medical and Pharmacological Sciences, vol. 23, no. 1, pp. 137-145, 2019.

[32] S. Xu, P. Wang, J. Zhang et al., "Ai-lncRNA EGOT enhancing autophagy sensitizes paclitaxel cytotoxicity via upregulation of ITPR1 expression by RNA-RNA and RNA-protein interactions in human cancer," Molecular Cancer, vol. 18, no. 1, 89 pages, 2019.

[33] Y. Messai, M. Z. Noman, B. Janji, M. Hasmim, B. Escudier, and S. Chouaib, "The autophagy sensor ITPR1 protects renal carcinoma cells from NK-mediated killing," Autophagy, 2015. 